\title{
The effects of ketolides on bioactive phospholipid-induced injury to human respiratory epithelium in vitro
}

\author{
C. Feldman*, R. Anderson ${ }^{+}$, A. Theron ${ }^{+}$, I. Mokgobu+, P.J. Cole ${ }^{\#}$, R. Wilson
}

\begin{abstract}
The effects of ketolides on bioactive phospholipid-induced injury to human respiratory epithelium in vitro. C. Feldman, R. Anderson, A. Theron, I. Mokgobu, P.J. Cole, R. Wilson. (C) ERS Journals Ltd 1999.

ABSTRACT: The potential of the novel ketolide antimicrobial agents, HMR 3004 and HMR 3647, to antagonize the injurious effects of the bioactive phospholipids (PL), platelet-activating factor (PAF), lyso-PAF, and lysophosphatidylcholine (LPC) on the ciliary beat frequency and structural integrity of human ciliated respiratory epithelium in vitro was investigated, in the presence or absence of polymorphonuclear leukocytes (PMNL).

The ciliary beat frequency of human nasal respiratory epithelium, obtained by nasal brushing of healthy volunteers, was measured using a photo-transistor technique, while superoxide generation by activated human PMNL and membranestabilizing activity were measured by lucigenin-enhanced chemiluminescence and haemolytic procedures, respectively.

All three PL, at concentrations of $2.5 \mu \mathrm{g} \cdot \mathrm{mL}^{-1}$, caused significant $(\mathbf{p}<0.005)$ ciliary slowing and epithelial damage, while treatment of the epithelial strips with the ketolides, in particular HMR 3004, caused dose-related attenuation of these direct adverse effects of the PL on ciliated epithelium, apparently by a membrane-stabilizing mechanism. When epithelial strips were exposed to the combination of PMNL $\left(1 \times 10^{6}\right.$ cells $\left.\cdot \mathrm{mL}^{-1}\right)$ and PAF $\left(1 \mu \mathrm{g} \cdot \mathrm{mL}^{-1}\right)$, significant ciliary dysfunction and epithelial damage were also observed, which were mediated predominantly by neutrophil-derived oxidants. These injurious effects of PAF were antagonized by preincubation of the epithelial strips or the PMNL with HMR $3004\left(10 \mu \mathrm{g} \cdot \mathrm{mL}^{-1}\right)$.

The ketolide antimicrobial agents, in particular HMR 3004, antagonize the direct and polymorphonuclear leukocyte-mediated injurious effects of phospholipids on human ciliated epithelium and may have beneficial effects in inflammatory disorders of the airways, such as asthma, chronic bronchitis, diffuse panbronchiolitis and bronchiectasis.
\end{abstract}

Eur Respir J 1999; 13: 1022-1028.

\begin{abstract}
*Division of Pulmonology, Dept of Medicine, Johannesburg Hospital and University of the Witwatersrand, South Africa. ${ }^{+}$MRC Unit for Inflammation and Immunity, Dept of Immunology, University of Pretoria, South Africa. "Host Defence Unit, Imperial College of Science, Technology and Medicine, National Heart and Lung Institute, UK.
\end{abstract}

Correspondence: C. Feldman

Dept of Medicine

University of the Witwatersrand Medical School

7 York Road

Parktown 2193

Johannesburg

South Africa

Fax: 27116438777

Keywords: Asthma

bioactive phospholipids

ciliary beat frequency

epithelial damage

ketolides

polymorphonuclear leukocytes

Received: September 81998

Accepted after revision February 21999

The study was sponsored by a grant from Hoechst Marion Roussel, France.
Asthma is now recognized to be an inflammatory condition of the airways [1-4]. A number of different cell types and molecules, including the bioactive phospholipids (PL), platelet-activating factor (PAF), lyso-PAF and lysophosphatidylcholine (LPC) have been suggested as being important mediators of this disease process [2, 5-11]. PAF, for example, is the only putative mediator able to elicit all the important manifestations of asthma [2, 5, 7], while it has previously been documented that the PL cause ciliary slowing, and damage to human ciliated epithelium in vitro, particularly in the presence of polymorphonuclear leukocytes (PMNL) [12].

Given the inflammatory nature of asthma, it is not surprising that current treatment guidelines stress the need for anti-inflammatory agents for therapy, with corticosteroids, preferably by the inhalational route, being recommended for the treatment of all but the very mildest of cases [13]. More recently, the macrolide antimicrobial agents have been studied and shown to be effective in the treatment of asthma [14-16]. However, the mechanisms by which macrolides improve asthma control are still uncertain. Some studies have suggested that the eradica- tion of Chlamydia pneumoniae infection may be important, while others have implicated the anti-inflammatory activity of these agents [17-21]. It has previously been reported that the beneficial, antiasthma effects of macrolides may be due to the ability of these agents to inhibit reactive oxidant release from PL-sensitized PMNL, most likely as a consequence of their membrane-stabilizing activity $[12,22]$.

However, asthma is not the only inflammatory disorder of the airway for which macrolide antibiotics have been shown to have a beneficial effect. Diffuse panbronchiolitis is a chronic infectious airway disease that occurs mainly in the Far East [23]. While this condition was previously associated with a very poor prognosis, the outcome has improved dramatically with the use of low-dose longterm erythromycin treatment [23]. The beneficial effects of erythromycin and other 14-membered-ring macrolides in this condition are considered to be due to anti-inflammatory rather than anti-infective mechanisms [23]. In vitro studies demonstrating the beneficial effects of erythromycin on Pseudomonas aeruginosa and neutrophilmediated epithelial damage suggest that use of these 
agents may also lead to clinical improvement in patients with chronic bronchial sepsis colonized by P. aeruginosa [24].

The two antimicrobial agents investigated in the present study, HMR 3004 (formerly known as RU64004) and HMR 3647, belong to a new subgroup of macrolides known as ketolides $[25,26]$. These agents differ structurally from erythromycin, the prototype macrolide, by having a 3-keto group instead of an L-cladinose at position 3 on the erythronilide ring [27]. HMR 3004 has a quinoline side-chain linked to the 11-12 position on the lactone nucleus by a cyclic hydrazono-carbamate function [27], while HMR 3647 has imidazol and pyridinyl side-chains at the corresponding position. These agents are being developed for antibiotic use, having a broad spectrum of activity against clinically important respiratory pathogens, including Gram-positive, Gram-negative and so-called "atypical" pathogens [25, 26]. However, little is known about their anti-inflammatory potential.

The aim of the present investigation was to determine the ability of HMR 3004 and HMR 3647 to attenuate the injurious effects of the PL on human ciliated epithelium in vitro.

\section{Methods}

\section{Ketolides}

HMR 3004 and HMR 3647 were kindly provided by Hoechst Marion Roussel (Romainville, France). These agents were dissolved to a stock concentration of 5 $\mathrm{mg} \cdot \mathrm{mL}^{-1}$ by the addition of $10 \mathrm{mg}$ of the dry powder to 2 $\mathrm{mL}$ of $0.05 \mathrm{~N} \mathrm{HCl}$. Subsequent dilutions were made in Hank's balanced salt solution (HBSS; pH 7.4, Highveld Biological, Johannesburg, South Africa) and the antimicrobial agents were used at final concentrations between $1-20 \mu \mathrm{g} \cdot \mathrm{mL}^{-1}$.

\section{Other chemicals and reagents}

Unless otherwise stated the chemicals and reagents were obtained from the Sigma Chemical Co. (St Louis, MO, USA).

\section{Polymorphonuclear leukocytes}

Human PMNL were obtained from heparinized (5 U preservative free heparin $\cdot \mathrm{mL}^{-1}$ ) venous blood of healthy adult volunteers and separated from mononuclear leukocytes by centrifugation on Ficoll-Paque (Pharmacia Fine Chemicals, Uppsala, Sweden) - metrizoate (Nyegaard, Oslo, Norway) cushions at $400 \times g$ for $25 \mathrm{~min}$ at room temperature. The resultant pellet was suspended in phosphate-buffered saline (PBS; $0.15 \mathrm{M}, \mathrm{pH} 7.4$ ) and sedimented with $3 \%$ gelatin for $15 \mathrm{~min}$ at $37^{\circ} \mathrm{C}$ to remove most of the erythrocytes. After centrifugation, erythrocytes were removed by selective lysis with $0.84 \%$ ammonium chloride at $4{ }^{\circ} \mathrm{C}$ for $10 \mathrm{~min}$. The PMNL were routinely of high purity and viability and were resuspended to $1 \times 10^{7}$ cells $\cdot \mathrm{mL}^{-1}$ in PBS and held on ice until used. The final concentration of PMNL used in the experiments with ciliated epithelium was $1 \times 10^{6}$ cells $\cdot \mathrm{mL}^{-1}$. Preliminary studies demonstrated that at this concentration the PMNL alone had no effect on ciliated epithelium over the time course of the experiments.

\section{Human ciliated epithelium}

Human ciliated epithelium was obtained by brushing of the inferior nasal turbinate of healthy human volunteers using a $2 \mathrm{~mm}$ bronchoscopy cytology brush, as described previously [28]. The study protocol was unconditionally approved by the Committee for Research on Human Subjects of the University of the Witwatersrand. For each experiment, fresh strips of ciliated epithelium were obtained from a single volunteer. The strips were suspended in HBSS. The specimen obtained was divided into 3 or 4 aliquots of $2 \mathrm{~mL}$ each which were centrifuged at $150 \times g$ for $10 \mathrm{~min}$. Thereafter the supernatant from each aliquot was aspirated and the epithelial strips resuspended in 800 $\mu \mathrm{L}$ of either control or test solution.

A closed microscope coverslip-slide preparation was constructed for each of the control or test preparations as described previously [28]. The specimens were randomized by an independent observer and coded. After an initial 10 -min incubation at $37^{\circ} \mathrm{C}$, the specimens were individually placed on an electronically controlled warmstage at $37^{\circ} \mathrm{C}$ (Sensicon LHE Laboratories, UK) on a Leitz Orthoplan phase contrast microscope (Leitz, Wetzlar, Germany). In each preparation 6-10 strips of epithelium were identified and one or two areas on each strip marked on the slide for later examination. The ciliary beat frequency (CBF) was measured at each of these areas by a photo-transistor technique which has been described previously [29]. In brief, the epithelial strips were orientated such that the ciliary beat interrupted a beam of light in their pathway. This modulation in light intensity was sensed by the photo-transistor, the electrical signal generated was amplified and optimized by visualization on an oscilloscope screen and then converted into a digital readout of $\mathrm{CBF}$. Ten readings were taken from each preparation at each time point. The mean CBF was calculated from these 10 readings. Values are expressed as the mean \pm SEM. Per cent slowing of CBF (per cent ciliary slowing $(\% \mathrm{CS})$ ) was calculated as the mean control $\mathrm{CBF}$ minus the mean test $\mathrm{CBF}$ divided by the mean control $\mathrm{CBF} \times 100$.

In addition, the percentage of strips with epithelial damage was measured using a visual scoring index as described previously [24]. Briefly, at each site of measurement of $\mathrm{CBF}$, disruption of the integrity of the epithelial surface (irregularity and break-up of the previously intact smooth surface) was recorded. Epithelial disruption was assessed subjectively in each strip by the same investigator and scored as either being present or absent. Disruption varied from extrusion of cells from the surface giving an uneven contour, to total break-up of the epithelial strip. No attempt was made to grade this abnormality.

This procedure was used to investigate the following:

1) The direct effects of PL alone on human ciliated epithelium in the absence and presence of HMR 3004 or HMR 3647. In these experiments, control preparations 
contained epithelial strips in HBSS alone, while test preparations contained epithelial strips exposed to the individual PL, namely PAF, lyso-PAF, and LPC (final concentration $\left.2.5 \mu \mathrm{g} \cdot \mathrm{mL}^{-1}\right)$ in the absence or presence of HMR 3004 (1$\left.20 \mu \mathrm{g} \cdot \mathrm{mL}^{-1}\right)$. Epithelial strips were preincubated with HMR 3004 at $37^{\circ} \mathrm{C}$ for $30 \mathrm{~min}$ prior to the addition of the PL. Preliminary experiments had demonstrated that at concentrations of up to $20 \mu \mathrm{g} \cdot \mathrm{mL}^{-1}$, neither HMR 3004 nor HMR 3647 per se had any effects on CBF or structural integrity of human ciliated epithelium over $4 \mathrm{~h}$ (mean \pm SEM, CBF of control strips were $11.7 \pm 0.30 \mathrm{~Hz}$ and with addition of $20 \mu \mathrm{g} \cdot \mathrm{mL}^{-1}$ of HMR $3647,12.0 \pm 0.26 \mathrm{~Hz}$ after $4 \mathrm{~h}$, and mean CBF of control strips $11.4 \pm 0.31 \mathrm{~Hz}$ and with addition of $20 \mu \mathrm{g} \cdot \mathrm{mL}^{-1}$ of HMR $3004,11.2 \pm 0.25 \mathrm{~Hz}$ after $4 \mathrm{~h}$ ). There was no epithelial damage. In an additional series of experiments, the protective effects of HMR 3004, at a fixed final concentration of $20 \mu \mathrm{g} \cdot \mathrm{mL}^{-1}$, on PL-mediated epithelial dysfunction and damage were compared with those of HMR 3647.

2) The effects of PAF in combination with PMNL on human ciliated epithelium in the absence and presence of HMR 3004. In these experiments, control preparations contained epithelial strips and PMNL (final concentration $1 \times 10^{6}$ cells $\left.\cdot \mathrm{mL}^{-1}\right)$ in HBSS alone, and test preparations contained epithelial strips exposed to PAF $\left(1 \mu \mathrm{g} \cdot \mathrm{mL}^{-1}\right)$ treated PMNL (final concentration $1 \times 10^{6}$ cells $\cdot \mathrm{mL}^{-1}$ ). To study the effects of HMR 3004, two additional systems were used. In the first of these, the epithelial strips were preincubated with HMR $3004\left(37^{\circ} \mathrm{C}\right.$ for $30 \mathrm{~min}$; final concentration of $\left.10 \mu \mathrm{g} \cdot \mathrm{mL}^{-1}\right)$ prior to the addition of PAF $\left(1 \mu \mathrm{g} \cdot \mathrm{mL}^{-1}\right)$-treated PMNL $\left(1 \times 10^{6}\right.$ cells $\left.\cdot \mathrm{mL}^{-1}\right)$, while in the second system the PMNL $\left(1 \times 10^{6}\right.$ cells $\left.\cdot \mathrm{mL}^{-1}\right)$ were preincubated with HMR $3004\left(37^{\circ} \mathrm{C}\right.$ for $30 \mathrm{~min}$; final concentration of $\left.10 \mu \mathrm{g} \cdot \mathrm{mL}^{-1}\right)$, prior to the addition of PAF $\left(1 \mu \mathrm{g} \cdot \mathrm{mL}^{-1}\right)$ and mixing with the epithelial strips. Preliminary experiments had demonstrated that concentrations of PL of $2.5 \mu \mathrm{g} \cdot \mathrm{mL}^{-1}$ (in experiments without PMNL) and $1 \mu \mathrm{g} \cdot \mathrm{mL}^{-1}$ (in experiments with PMNL) of the PL were optimum for studying their effects on ciliated epithelium (i.e. there were sufficient effects on ciliated epithelium to be able to monitor the response of the ketolides without there being complete disruption of the tissue).

3) The effects of PAF and LPC in combination with PMNL on human ciliated epithelium in the absence and presence of catalase and/or superoxide dismutase. In these experiments, control preparations contained epithelial strips and PMNL (final concentration $1 \times 10^{6}$ cells $\cdot \mathrm{mL}^{-1}$ ), and test preparations contained epithelial strips exposed to PAF (1 $\left.\mu \mathrm{g} \cdot \mathrm{mL}^{-1}\right)$ - or LPC $\left(1 \mu \mathrm{g} \cdot \mathrm{mL}^{-1}\right)$-treated PMNL (final concentration $1 \times 10^{6}$ cells $\left.\cdot \mathrm{mL}^{-1}\right)$. Additional preparations of epithelial strips were preincubated with either catalase alone $\left(1,500 \mathrm{U} \cdot \mathrm{mL}^{-1}\right.$ from bovine liver) or superoxide dismutase alone $\left(100 \mathrm{U} \cdot \mathrm{mL}^{-1}\right.$ from bovine liver) or both, at $37^{\circ} \mathrm{C}$ for $30 \mathrm{~min}$, prior to the addition of PAF- or LPCtreated PMNL.

\section{Superoxide production}

This was measured using a lucigenin (bis- $N$-methylacridinium nitrate)-enhanced chemiluminescence (LECL) method [29]. PMNL were preincubated for $15 \mathrm{~min}$ at room temperature in $900 \mu \mathrm{L}$ HBSS containing $0.2 \mathrm{mM}$ lucigenin in the presence and absence of HMR 3004 and HMR $3647\left(5-40 \mu \mathrm{g} \cdot \mathrm{mL}^{-1}\right)$ followed by $15 \mathrm{~min}$ at $37^{\circ} \mathrm{C}$. Spontaneous LECL responses and those activated by PAF and LPC were then recorded in an LKB Wallac 1251 chemiluminometer (Turku, Finland) after the addition of $100 \mu \mathrm{L}$ of each bioactive PL (final concentrations of 5 and $10 \mu \mathrm{g} \cdot \mathrm{mL}^{-1}$ ).

Superoxide-scavenging activity of the test agents was investigated using a cell-free xanthine $(1 \mathrm{mM})$-xanthine oxidase $\left(70 \mathrm{mU} \cdot \mathrm{mL}^{-1}\right)$ superoxide-generating system.

\section{Membrane stabilization}

The membrane stabilizing potential of the test agents was determined using a haemolytic assay. Sheep erythrocytes were washed 3-times and resuspended to $5 \%$ in HBSS. The erythrocytes (final concentration of $0.5 \%$ ) were then coincubated with the ketolides $\left(10-40 \mu \mathrm{g} \cdot \mathrm{mL}^{-1}\right)$ for $30 \mathrm{~min}$ at $37^{\circ} \mathrm{C}$ followed by the addition of LPC, PAF or lyso-PAF at concentrations $\left(2.5-4 \mu \mathrm{g} \cdot \mathrm{mL}^{-1}\right)$ which caused partial haemolysis. After $5 \mathrm{~min}$, intact erythrocytes were removed by centrifugation and the supernatants assayed spectrophotometrically at $405 \mathrm{~nm}$ for haemoglobin content.

\section{Statistical analysis}

The results of each series of experiments are expressed as the means \pm SEM. Effects on CBF and amount of epithelial damage were compared in control and test preparations by means of the Mann-Whitney U-test (two-tail). For superoxide and membrane stabilizing experiments, the data were analysed by means of the Students t-test. A pvalue of $<0.05$ was considered to be significant. Unless otherwise indicated each set of experiments was performed at least 6 times, using $\geq 6$ different nasal brushing preparations.

\section{Results}

The direct effects of PL alone on human ciliated epithelium in the absence and presence of HMR 3004

The results of these experiments are shown in table 1. PAF, lyso-PAF and LPC (final concentration 2.5 $\mu \mathrm{g} \cdot \mathrm{mL}^{-1}$ ) caused significant ciliary slowing (range 14$23 \%$ ) and damage to structural integrity (range $28-35 \%$ ) of human ciliated epithelium in vitro. Inclusion of HMR $3004\left(20 \mu \mathrm{g} \cdot \mathrm{mL}^{-1}\right)$ antagonized these injurious effects of the PL on the epithelium.

Results of dose-response experiments using varying concentrations of HMR $3004\left(1-10 \mu \mathrm{g} \cdot \mathrm{mL}^{-1}\right)$ and a fixed concentration of PAF $\left(2.5 \mu \mathrm{g} \cdot \mathrm{mL}^{-1}\right)$ are shown in table 2 . Equivalent antagonism of the injurious effects of the PL was observed with HMR 3004 at concentrations of 10 and $20 \mu \mathrm{g} \cdot \mathrm{mL}^{-1}$, while with lower concentrations of the antimicrobial agent less effective antagonism was observed.

The comparative effects of HMR 3004 and HMR 3647 at a fixed concentration of $20 \mu \mathrm{g} \cdot \mathrm{mL}^{-1}$ on PL-mediated 
Table 1. - The mean \pm SEM ciliary beat frequency (CBF) and per cent ciliary slowing (\%CS) and epithelial damage (\%ED) in epithelial strips exposed to bioactive phospholipids (PL) in the absence and presence of HMR 3004

\begin{tabular}{|c|c|c|c|c|c|c|c|c|}
\hline & \multicolumn{2}{|c|}{$\begin{array}{l}\text { Control strips } \\
\text { (in HBSS alone) }\end{array}$} & \multicolumn{3}{|c|}{$\begin{array}{l}\text { Epithelial strips exposed to PL } \\
\left(2.5 \mu \mathrm{g} \cdot \mathrm{mL}^{-1}\right)\end{array}$} & \multicolumn{3}{|c|}{$\begin{array}{l}\text { Epithelial strips incubated with HMR } 3004 \\
\left(20 \mu \mathrm{g} \cdot \mathrm{mL}^{-1}\right) \text { prior to exposure to PL }\end{array}$} \\
\hline & $\mathrm{CBF} \mathrm{Hz}$ & $\% \mathrm{ED}$ & CBF Hz & $\% \mathrm{ED}$ & $\% \mathrm{CS}$ & CBF Hz & $\% \mathrm{ED}$ & $\% \mathrm{CS}$ \\
\hline PAF* ${ }^{*}$ & $11.4 \pm 0.17$ & 0 & $8.8 \pm 0.38^{+}$ & $35^{+}$ & 23 & $11.6 \pm 0.18$ & 0 & 0 \\
\hline Lyso-PAF* & $11.5 \pm 0.17$ & 0 & $8.9 \pm 0.38^{+}$ & $33^{+}$ & 23 & $11.8 \pm 0.16$ & 0 & 0 \\
\hline LPC* & $11.1 \pm 0.15$ & 0 & $9.5 \pm 0.40^{+}$ & $28^{+}$ & 14 & $11.1 \pm 0.23$ & 7 & 0 \\
\hline
\end{tabular}

PAF: platelet-activating factor; LPC: lysophosphatidylcholine. *: only added to epithelial strips exposed to PL; ${ }^{+}: \mathrm{p}<0.005$ versus control. All other values not significantly different from control.

epithelial cell damage and dysfunction are shown in table 3. HMR 3004 caused almost complete antagonism of the injurious effects of the PL on the epithelium. Similar, but much less striking, effects were noted with HMR 3647.

The effects of PAF in combination with PMNL on human ciliated epithelium in the absence and presence of HMR 3004

These results are shown in table 4. PAF $\left(1 \mu \mathrm{g} \cdot \mathrm{mL}^{-1}\right)$ added to PMNL $\left(1 \times 10^{6}\right.$ cells $\left.\cdot \mathrm{mL}^{-1}\right)$ followed by immediate addition to the strips caused significant ciliary slowing and epithelial damage. These effects were partially antagonized by preincubation of the epithelial strips with HMR $3004\left(37^{\circ} \mathrm{C}\right.$ for $30 \mathrm{~min}$; final concentration 10 $\left.\mu \mathrm{g} \cdot \mathrm{mL}^{-1}\right)$ and were almost completely abolished by preincubation of the PMNL with HMR 3004 prior to the addition of PAF followed by exposure to the epithelial strips.

The effects of PAF and LPC in combination with PMNL on human ciliated epithelium in the absence and presence of catalase and/or superoxide dismutase

Catalase alone $\left(1,500 \mathrm{U} \cdot \mathrm{mL}^{-1}\right)$ and in combination with superoxide dismutase $\left(100 \mathrm{U} \cdot \mathrm{mL}^{-1}\right)$ almost completely abolished the injurious effects of PAF $\left(1 \mu \mathrm{g} \cdot \mathrm{mL}^{-1}\right)$ - and LPC $\left(1 \mu \mathrm{g} \cdot \mathrm{mL}^{-1}\right)$-treated PMNL $\left(1 \times 10^{6}\right.$ cells $\left.\cdot \mathrm{mL}^{-1}\right)$ on the epithelium. For the experiments with PAF, the mean \pm SEM $\mathrm{CBF}$ and per cent epithelial damage of the control strips were $11.8 \pm 0.2 \mathrm{~Hz}$ and $0 \%$, respectively, while the cor-

Table 2. - The mean \pm SEM ciliary beat frequency (CBF) and per cent ciliary slowing $(\% \mathrm{CS})$ and per cent epithelial damage (\%ED) induced in epithelial strips by exposure to platelet-activating factor (PAF) in the presence and absence of HMR 3004

\begin{tabular}{lccc}
\hline & $\mathrm{CBF} \mathrm{Hz}$ & $\% \mathrm{ED}$ & $\% \mathrm{CS}$ \\
\hline $\begin{array}{l}\text { Control epithelial strips } \\
\text { Epithelial strips exposed to PAF }\end{array}$ & $11.9 \pm 0.05$ & - & - \\
$\quad\left(2.5 \mu \mathrm{g} \cdot \mathrm{mL}^{-1}\right)$ & $8.9 \pm 0.26^{+}$ & $32^{+}$ & 25 \\
Epithelial strips exposed to PAF & & & \\
with prior incubation with & & & \\
$\mathrm{HMR} 3004$ at: & & & \\
$1 \mu \mathrm{g} \cdot \mathrm{mL}^{-1}$ & $10.1 \pm 0.31^{+}$ & $23^{+}$ & 15 \\
$5 \mu \mathrm{g} \cdot \mathrm{mL}^{-1}$ & $10.1 \pm 0.31^{+}$ & $23^{+}$ & 15 \\
$10 \mu \mathrm{g} \cdot \mathrm{mL}^{-1}$ & $11.6 \pm 0.14$ & 3 & 3 \\
\hline
\end{tabular}

${ }^{+}: \mathrm{p}<0.005$ versus control; values for $10 \mu \mathrm{g} \cdot \mathrm{mL}^{-1} \mathrm{HMR} 3004$ were not significantly different from control but were significantly different $(p<0.005)$ from all other values. responding values for the systems treated with PAF and PMNL in the absence of antioxidative enzymes and in the presence of catalase only, superoxide dismutase only, and both catalase and superoxide dismutase were $9.1 \pm 0.2 \mathrm{~Hz}$ and $40 \%, 11.8 \pm 0.1 \mathrm{~Hz}$ and $0 \%, 9.6 \pm 0.4 \mathrm{~Hz}$ and $35 \%$ and $11.9 \pm 0.2 \mathrm{~Hz}$ and $0 \%$, respectively.

For the experiments with LPC, the mean \pm SEM CBF and per cent epithelial damage of control strips were $10.8 \pm 0.2$ $\mathrm{Hz}$ and $0 \%$, respectively, while the corresponding values for systems treated with LPC and PMNL in the absence of the antioxidative enzymes and in the presence of catalase alone, superoxide dismutase alone, or both catalase and superoxide dismutase were $7.9 \pm 0.4 \mathrm{~Hz}$ and $45 \%, 10.1 \pm 0.3$ $\mathrm{Hz}$ and $15 \%, 7.8 \pm 0.1 \mathrm{~Hz}$ and $40 \%$, and $10.8 \pm 0.1 \mathrm{~Hz}$ and $0 \%$, respectively.

Effects of the ketolides on superoxide production by $P M N L$

At concentrations of 5 and $10 \mu \mathrm{g} \cdot \mathrm{mL}^{-1}$, PAF and LPC caused activation of superoxide by PMNL, which was significantly inhibited in a dose-related manner by both ketolides, particularly HMR 3004. The results for PAF and LPC at $10 \mu \mathrm{g} \cdot \mathrm{mL}^{-1}$ are shown in figure 1 .

Table 3. - The mean \pm SEM per cent ciliary slowing (\%CS) and epithelial damage (\%ED) induced in epithelial strips exposed to bioactive phospholipids (PL) and the comparative ability of the ketolide agents HMR 3004 and HMR 3647 (final concentration $20 \mu \mathrm{g} \cdot \mathrm{mL}^{-1}$ ) to attenuate these effects

\begin{tabular}{ccc} 
PL alone & Preincubation & Preincubation \\
(2.5 $\left.\mu \mathrm{g} \cdot \mathrm{mL}^{-1}\right)$ & with & with \\
& HMR 3004** & HMR 3647** \\
\hline
\end{tabular}

\begin{tabular}{lccr}
\hline PAF & & & \\
$\%$ CCS & $17 \pm 4.4$ & 0 & $4 \pm 2.5$ \\
\%ED & $30 \pm 0.0$ & 0 & $15 \pm 5.0$ \\
$\begin{array}{l}\text { Lyso-PAF } \\
\% C S\end{array}$ & $19 \pm 0.6$ & 0 & $3 \pm 0.5$ \\
$\%$ ED & $30 \pm 0.0$ & 0 & $5 \pm 5.0$ \\
LPC & & & \\
$\% \mathrm{CS}$ & $14 \pm 4.2$ & $2 \pm 0.5$ & $8 \pm 0.1$ \\
$\% \mathrm{ED}$ & $30 \pm 0.0$ & $5 \pm 0.0$ & $20 \pm 0.0$ \\
\hline
\end{tabular}

PAF: platelet-activating factor; LPC: lysophosphatidylcholine. **: In these systems, epithelial strips were preincubated for 30 $\min$ at $37^{\circ} \mathrm{C}$ with the ketolide prior to the addition of the PL. The mean \pm SEM ciliary beat frequency for each control system was $11.6 \pm 0.40 \mathrm{~Hz}, 11.9 \pm 0.10 \mathrm{~Hz}$ and $11.6 \pm 0.20 \mathrm{~Hz}$, respectively. There was no epithelial damage in any of the control systems. 
Table 4. - Mean \pm SEM ciliary beat frequency (CBF) and per cent ciliary slowing (\%CS) and epithelial damage (\%ED) in human ciliated respiratory epithelium exposed to platelet-activating factor (PAF)-sensitized polymorphonuclear leukocytes (PMNL) in the presence and absence of HMR 3004 (final concentration $10 \mu \mathrm{g} \cdot \mathrm{mL}^{-1}$ )

\begin{tabular}{|c|c|c|c|}
\hline & $\mathrm{CBF} \mathrm{Hz}$ & $\% \mathrm{ED}$ & $\% \mathrm{CS}$ \\
\hline Control epithelial strips & $11.5 \pm 0.22$ & - & - \\
\hline $\begin{array}{l}\text { Epithelial strips exposed to PAF } \\
\left(1 \mu \mathrm{g} \cdot \mathrm{mL}^{-1}\right)\end{array}$ & $9.5 \pm 0.38^{+}$ & $33^{+}$ & 17 \\
\hline $\begin{array}{l}\text { Preincubation of epithelial strips } \\
\text { with HMR } 3004\end{array}$ & $10.5 \pm 0.27 *$ & $17^{*}$ & 9 \\
\hline $\begin{array}{l}\text { Preincubation of PMNL with } \\
\text { HMR } 3004\end{array}$ & $11.4 \pm 0.14^{\#}$ & $3^{\#}$ & $<1$ \\
\hline
\end{tabular}

${ }^{+}: \mathrm{p}<0.005$ versus control; *: $\mathrm{p}<0.05$ versus control; ${ }^{\#}:$ not significantly different from control, but significantly different $(\mathrm{p}<$ $0.05)$ from all other values.

\section{Membrane stabilizing activity of the ketolides}

These results are shown in figure 2 . Both ketolides, but HMR 3004 in particular, caused dose-related antagonism of the haemolytic effects of all three bioactive PL.

\section{Discussion}

In this study, it has been demonstrated that exposure to the bioactive PL, PAF, lyso-PAF and LPC in vitro causes ciliary slowing and disruption of the structural integrity of the human respiratory epithelium, which is potentiated in the presence of neutrophils. Inclusion of either ketolide, particularly the prototype HMR 3004, attenuated these injurious interactions of all three PL with ciliated epithelium in both the presence and absence of neutrophils. The superior antagonistic activity of HMR 3004 may be related to its remarkable level of intracellular accumulation by eukaryotic cells, which in the case of human neutrophils, is $\sim 450$-fold higher than extracellular concentrations, in comparison with HMR 3647, which has a corresponding intracellular/extracellular ratio of $\geq 200$ in vitro [27].

The present study confirms previous findings [12], that PL cause slowing of CBF and epithelial damage at concentrations $>1 \mu \mathrm{g} \cdot \mathrm{mL}^{-1}$. These effects are dose-dependent, are irreversible, and are enhanced in the presence of PMNL [12]. At concentrations of PL of $\geq 20 \mu \mathrm{g} \cdot \mathrm{mL}^{-1}$, LPC caused complete ciliostasis and $100 \%$ epithelial damage [12]. The concentrations of PL used in the present study were derived from previous experience with these agents and were chosen because they caused partial damage to the ciliated epithelium, without there being complete disruption of the tissue. There appears to be two distinct mechanisms of PL injury to the ciliated epithelium demonstrated in these studies. In the experiments conducted in which PMNL were not added to the epithelial strips, the mechanism of injury appears to be simply a direct, nonspecific effect, as a result of the detergent-like, membrane-disruptive activity of the PL $[12,30]$. Other investigators [31], reporting on the detrimental effects of $P$. aeruginosa-derived bacterial products on ciliary function, in a similar fashion, have suggested that in their system the mechanism involved neutrophils and toxic oxygen radicals. This does not appear to be the case in the present
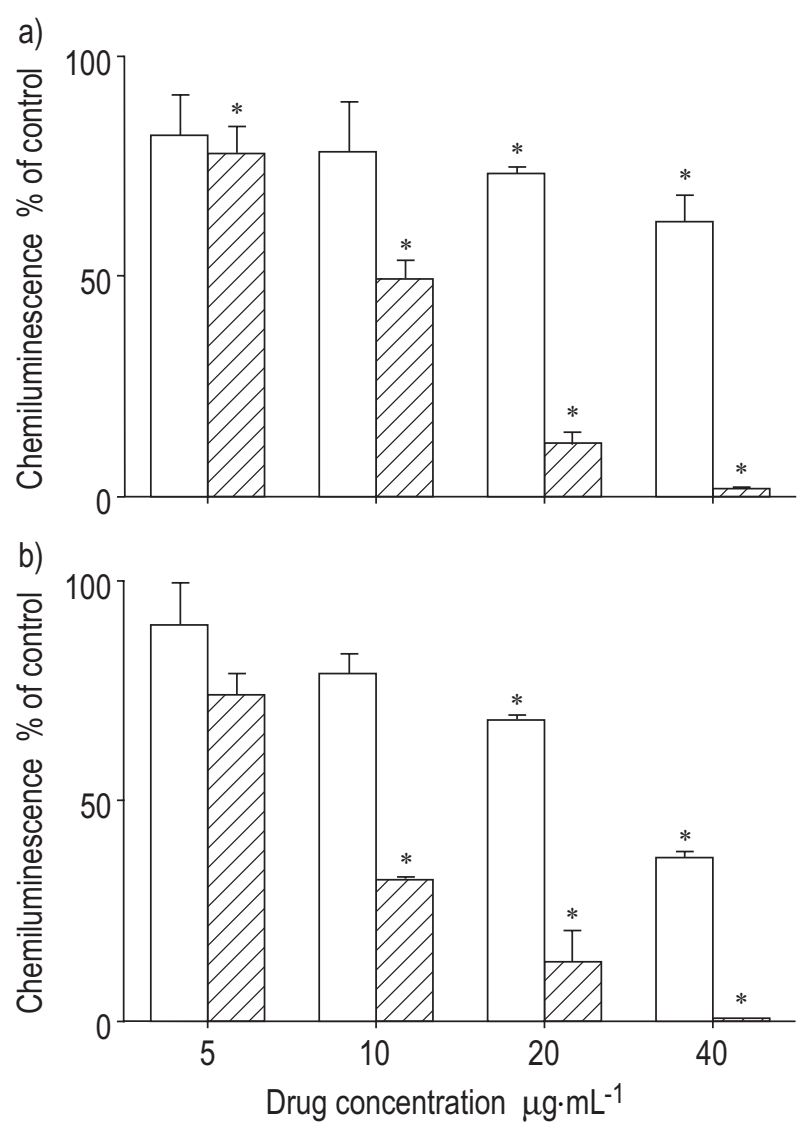

Fig. 1. - The effects of the ketolides, HMR $3004(\mathbb{Z})$ and HMR 3647 ( $\square$ ) $\left(5-40 \mu \mathrm{g} \cdot \mathrm{mL}^{-1}\right)$, on platelet-activating factor (PAF; a) and lysophosphatidylcholine (LPC; b) $\left(10 \mu \mathrm{g} \cdot \mathrm{mL}^{-1}\right)$-activated superoxide production by human polymorphonuclear leukocytes. The results are expressed as the mean percentage of the peak, drug-free control systems \pm SEM. Peak values occurred at $7 \pm 0.5$ min after addition of PAF or PLC. The absolute values for the unstimulated and PAF/LPC-stimulated control systems were $297 \pm 18$ and $1,958 \pm 185 \mathrm{mV} \cdot \mathrm{s}^{-1}$, respectively. ${ }^{*}: \mathrm{p}<0.05-\mathrm{p}<0.002$.

experimental model for two reasons. Firstly, neither catalase nor superoxide dismutase individually or in combination, protected the epithelial strips in the absence of PNML, and secondly, no PMNL were visualized in the preparations [12]. However, in experiments in which PMNL was added to the epithelial strips, direct membrane damage is definitely and significantly potentiated by reactive oxidant release from PL-activated PMNL [12]. In this situation, PMNL could clearly be visualized in the preparations and catalase alone and in combination with superoxide dismutase significantly decreased the effects of PL on the epithelium [12].

While a previous study of macrolides demonstrated that these agents attenuated only the indirect injury caused by reactive oxidant release from PL-activated PMNL [12], the ketolide antimicrobial agents used in the current study attenuated both the direct and indirect forms of PLinduced epithelial injury. These protective effects of HMR 3004 and HMR 3647 may be related to their ability, as documented in the present study, to stabilize the outer membrane of eukaryotic cells, thereby increasing its resistance to attack by membrane damaging PL. The membrane stabilizing activity of HMR 3004 and HMR 3647, a property which they share with conventional macrolides 

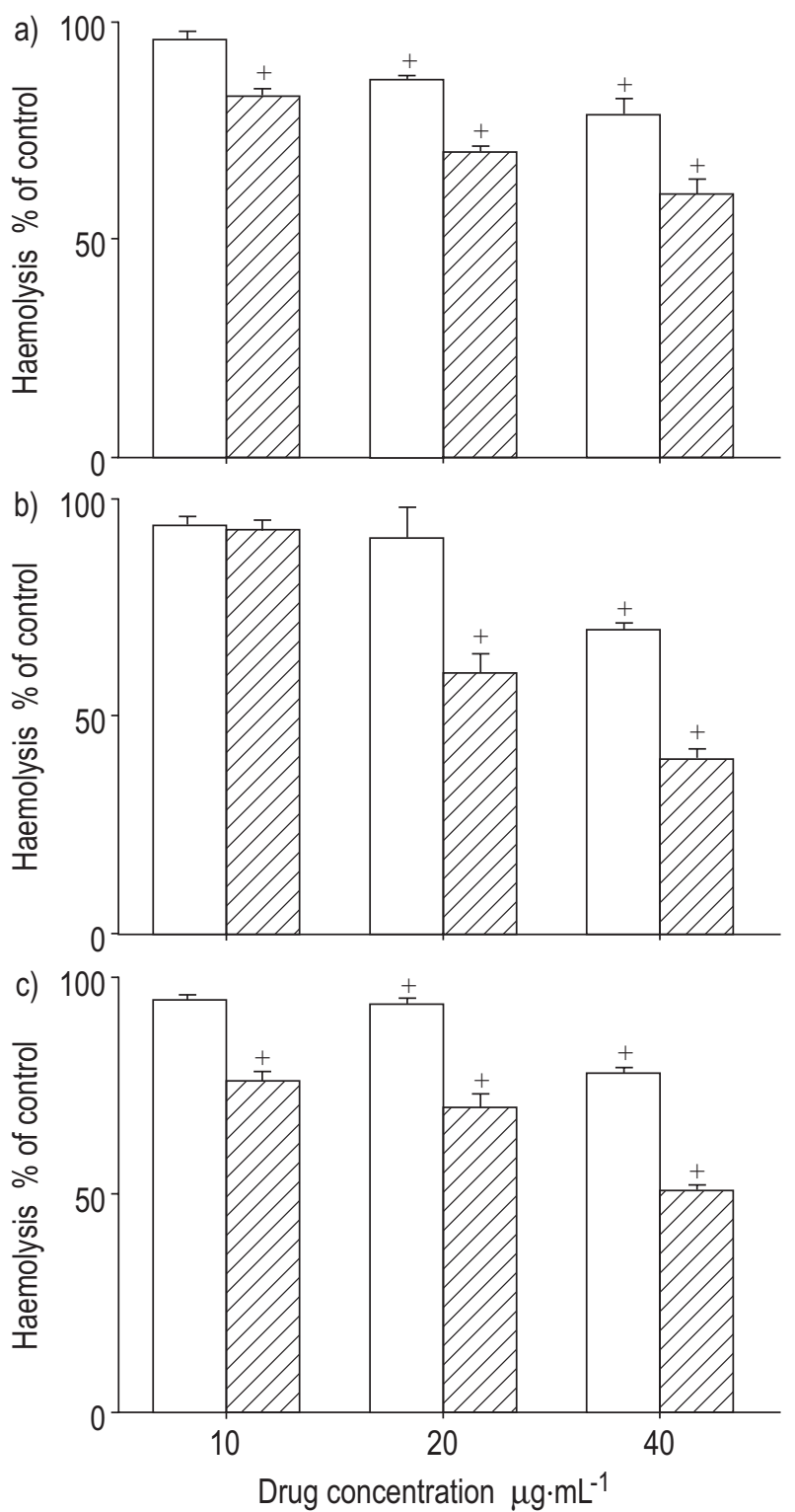

Fig. 2. - The membrane stabilizing activity of the ketolides HMR 3004 $(\mathbb{Z})$ and HMR $3647(\square)$ (concentrations $10-40 \mu \mathrm{g} \cdot \mathrm{mL}^{-1}$ ) as demonstrated in a haemolytic assay. The mean percentages haemolysis in a) lysoplatelet-activating factor (PAF), b) PAF- and c) lysophosphatidylcholine (LPC)-created systems in the absence of the ketolides were $54 \pm 1 \%$, $57 \pm 1.3 \%$ and $50 \pm 0.5 \%$, respectively. ${ }^{+}: \mathrm{p}<0.04-\mathrm{p}<0.0005$.

[22], was demonstrated using a haemolytic procedure, whereby pretreatment of erythrocytes with the ketolides was accompanied by antagonism of the lytic effects of all three PL. HMR 3004 was found to have considerably more potent membrane stabilizing activity than HMR 3647 , with both ketolides being superior in this respect to roxithromycin, a semi-synthetic macrolide previously shown to possess membrane stabilizing properties, which were equal to those of clarithromycin and better than those of erythromycin and azithromycin [22]. The differences observed in the present study in membrane stabilizing activity may simply reflect increased uptake of HMR 3004 relative to that of HMR 3647 and the macrolides. The precise physicochemical mechanisms which enable ketolides and macrolides to stabilize the plasma membrane of neutrophils and other types of eukaryotic cell remain to be established, but do not appear to involve direct complex forming interactions of these agents with the PL [22].

Combining LPC, PAF or lyso-PAF with neutrophils resulted in augmentation of epithelial injury and dysfunction. In these experiments, inclusion of the ketolides, particularly HMR 3004, antagonized the damaging effects of PL-treated neutrophils on ciliated respiratory epithelium. Maximal reduction in neutrophil-mediated epithelial injury was afforded by preincubation of neutrophils with the ketolides prior to the exposure of these cells to the PL, as opposed to ketolide-pretreatment of the epithelial strips. Although direct protective interactions of the ketolides with the ciliated epithelium cannot be excluded, epithelial damage in this setting appears to be mediated primarily by neutrophil-derived oxidants. This contention is based on two lines of evidence. Firstly, all three PL caused doserelated activation of superoxide production by neutrophils, which was inhibited by both ketolides, particularly HMR 3004, and, secondly, the anti-oxidative enzymes, catalase and superoxide dismutase in combination, antagonized the epithelium-damaging effect of PL-treated neutrophils. Importantly, these pro-oxidative interactions of lysophosphatides with neutrophils are highly correlated with their membrane disruptive properties [32], as clearly demonstrated in the current study. It has previously been reported that the macrolide/azalide antimicrobial agents erythromycin, clarithromycin, roxithromycin and azithromycin inhibit superoxide generation by activated human neutrophils, apparently by a membrane stabilizing mechanism which may interfere with the protein motions, both lateral and rotational, that are necessary for optimum assembly and function of the multicomponent reduced nicotinamide adenine dinucleotide phosphate (NADPH) oxidase [33]. Similar membrane stabilizing mechanisms probably underlie the anti-oxidative interactions of the ketolides with neutrophils.

Macrolide antimicrobial agents have been shown to have a definite or potential role in a number of conditions affecting the airways, most of these effects being related to anti-inflammatory rather than antimicrobial activity. In diffuse panbronchiolitis, macrolides are firmly established as the basic treatment for this condition, and have had a major impact on the prognosis of such patients [23]. Asthma is recognized primarily as an inflammatory disorder of the airways and current treatment guidelines stress the need for early anti-inflammatory therapy. The mainstay of such therapy are the inhaled corticosteroids, which are considered to be effective and generally well tolerated [34]. However, questions are still raised regarding their role in certain categories of asthmatics [34, 35]. Studies are currently underway which are investigating the role of macrolides in the therapy of asthma [16]. More data also accumulating on the potential clinical benefit, beyond their antimicrobial activity, of macrolides in chronic bronchial sepsis, in cases colonized with $P$. aeruginosa, such as occurs in patients with cystic fibrosis and bronchiectasis [24]. The present data with the ketolides, demonstrating more potent anti-inflammatory effects than the conventional macrolides, suggests that these agents may also be shown to be of benefit in many of these patients. Importantly, the concentrations of ketolides used in the current experiments are close to those 
likely to be attained in serum following oral administration of these agents to humans (data from A. Bryskier, Hoechst Marion Roussel, Paris, France).

In conclusion, the current study demonstrates that the ketolide antimicrobial agents, in particular HMR 3004, protect human ciliated epithelium against the injurious effects of phospholipids, both directly and indirectly, and may have beneficial effects on airway inflammatory disorders such as asthma, chronic bronchitis, diffuse panbronchiolitis and bronchiectasis.

\section{References}

1. Djukanovic R, Roche WR, Wilson JW, et al. Mucosal inflammation in asthma. Am Rev Respir Dis 1990; 142: 434-457.

2. Barnes PJ, Chung KF, Page CP. Inflammatory mediators and asthma. Pharmacol Rev 1988; 40: 49-84.

3. Laitinen LA, Laitinen A, Altraja A, et al. Bronchial biopsy findings in intermittent or "early" asthma. $J$ Allergy Clin Immunol 1996; 98: S3-S6.

4. Laitinen LA, Laitinen A, Haatela T. Airway mucosal inflammation even in patients with newly diagnosed asthma. Am Rev Respir Dis 1993; 147: 697-704.

5. Barnes PJ. New concepts in the pathogenesis of bronchial hyperresponsiveness and asthma. J Allergy Clin Immunol 1989; 83: 1013-1026.

6. Metha D, Gupta S, Gaur SN, Gangal SV, Agrawal KP. Increased leukocyte phospholipase A2 activity and plasma lysophosphatidylcholine levels in asthma and rhinitis and their relationship to airway sensitivity to histamine. Am Rev Respir Dis 1990; 142: 157-161.

7. Louis R, Bury T, Corhay JL, Rademecker MF. Acute bronchial and hematologic effects following inhalation of a single dose of PAF. Comparison between asthmatics and normal subjects. Chest 1994; 106: 1094-1099.

8. Felez Ma, Roca J, Barbera JA, et al. Inhaled plateletactivating factor worsens gas exchange in mild asthma. Am J Respir Crit Care Med 1994; 150: 369-373.

9. Marquaudt DL, Walker LL. Lysophosphatidylcholine induces mast cell secretion and protein kinase $\mathrm{C}$ activation. J Allergy Clin Immunol 1991; 88: 721-730.

10. Chelton FH, Averill FJ, Hubbard WC, Fonteh AN, Triggiani M, Liu MC. Antigen-induced generation of lysophospholipids in human airways. J Exp Med 1996; 183: 2235-2245.

11. Chung KF. Platelet-activating factor revisited. Thorax 1997; 52: 1019-1020.

12. Feldman C, Anderson R, Theron AJ, Ramafi G, Cole PJ, Wilson R. Roxithromycin, clarithromycin and azithromycin attenuate the injurious effects of bioactive phospholipids on human respiratory epithelium in vitro. Inflammation 1997; 21: 655-665.

13. Fitzgerald JM, Spier S, Ernst P. Evidence-based asthma guidelines. Chest 1996; 110: 1382-1383.

14. Miyatake H, Taki F, Taniguchi H, Suzuki R, Takagi K, Satake T. Erythromycin reduces the severity of bronchial hyperresponsiveness in asthma. Chest 1991; 99: 670-673.

15. Shimizu T, Kato M, Mochizuki H, Tokuyama K, Morikawa A, Kurome T. Roxithromycin reduces the degree of bronchial hyperresponsiveness in children with asthma. Chest 1994; 106: 458-561.

16. Black PN. The use of macrolides in the treatment of asthma. Eur Respir Rev 1996; 6: 240-243.

17. Anderson R. Erythromycin and roxithromycin potentiate human neutrophil locomotion in vitro by inhibition of leukoattractant-activated superoxide generation and autooxidation. J Infect Dis 1989; 159: 966-973.

18. Labro MT, El Benna J, Babin-Chevaye C. Comparison of the in vitro effect of several macrolides on the oxidative burst of human neutrophils. J Antimicrob Chemother 1989; 24: 561-572.

19. Umeki S. Anti-inflammatory action of erythromycin: its inhibitory effect on neutrophil NADPH oxidase activity. Chest 1993; 104: 1191-1193.

20. Hand WL, Hand DL. Interactions of dirithromycin with human polymorphonuclear leukocytes. Antimicrob Agents Chemother 1993; 37: 2557-2562.

21. Akamatsu H, Nishijima S, Akamatsu M, Kurokawa I, Sasaki H, Asada Y. The effect of roxithromycin on the generation of reactive oxygen species in vitro. J Int Med Res 1996; 24: 27-32.

22. Anderson R, Theron AJ, Feldman C. Membrane stabilizing, anti-inflammatory interactions of macrolides with human neutrophils. Inflammation 1996; 20: 693-705.

23. Kudos S. Erythromycin treatment in diffuse panbronchiolitis. Curr Opin Pulmon Med 1998; 4: 116-121.

24. Tanaka E, Kanthakumar K, Cundell DR, et al. The effect of erythromycin on Pseudomonas aeruginosa and neutrophil mediated epithelial damage. J Antimicrob Chemother 1994; 33: 765-775.

25. Ednie LM, Spangler SK, Jacobs MR, Appelbaum PC. Susceptibilities of 228 penicillin- and erythromycin-susceptible and -resistant pneumococci to RU 64004, a new ketolide, compared with susceptibilities to 16 other agents. Antimicrob Agents Chemother 1997; 41: 1033-1036.

26. Schulin T, Wennersten CB, Moellering RC Jr, Eliopoulos GM. In vitro activity of RU 64004, a new ketolide antibiotic, against gram-positive bacteria. Antimicrob Agents Chemother 1997; 41: 1196-1202.

27. Vazifeh D, Abdelghaffar H, Labro MT. Cellular accumulation of the new ketolide RU 64004 by human neutrophils: comparison with that of azithromycin and roxithromycin. Antimicrob Agents Chemother 1997; 41: 2099-2107.

28. Rutland J, Cole PJ. Non-invasive sampling of nasal cilia for the measurement of beat frequency and ultrastructures. Lancet 1980; ii: 564-565.

29. Feldman C, Voorvelt A. A photo-transistor technique for the measurements of the ciliary beat frequency of human ciliated epithelium in vitro. S Afr J Sci 1994; 90: $555-556$.

30. Libondi T, Menzione M, Auricchio G. In vitro effects of alpha-tocopherol on lysophosphatidylcholine-induced lens damage. Exp Eye Res 1985; 40: 661-666.

31. Jackowski JT, Szepfalusi ZS, Wanner DA, et al. Effects of $P$. aeruginosa derived bacterial products on tracheal ciliary function: role of $\mathrm{O}_{2}$ radicals. Am J Physiol 1991; 260: L61-L67.

32. Ginsburg I, Ward PA, Varani J. Lysophosphatides enhance superoxide responses of stimulated human neutrophils. Inflammation 1989; 13: 163-174.

33. Kusner DJ, Aucott JN, Franceschi D, Sarasau MM, Spagnuolo SJ, King CH. Protease priming of neutrophil superoxide production: effects on membrane lipid order and lateral mobility. J Biol Chem 1991; 266: 1646516471.

34. Fabbri LM, Sterk PJ. The rationale for a new approach in asthma treatment. Eur Respir Rev 1997; 7: 253-258.

35. Aubier M. Issues concerning the anti-inflammatory treatment of mild asthma. Eur Respir Rev 1997; 7: 321-322. 